\title{
The Affordability Platform: Moving Towards Outcome-based Care Delivery
}

Richard Bakalar, David Gruber, Joel Reich

\section{The Third Wave of Telemedicine}

Joel Reich [00:37]

We've been talking about moving towards outcome-based care delivery, and away from fee for service, and getting it to the point where you are having the coordination and improving the delivery of the system, for a long time. I hope we're at an inflection point. So, I look forward to getting to know some of you in that capacity as the affordability platform leader and it's a pleasure to be here today.

Richard Bakalar [01:03]

I'm Rich Bakalar. I think the key is we're actually in the third wave of telemedicine. The first wave was individual physicians driving it, basically trying to avoid traffic and avoid the transportation challenges in downtown Boston 50 years ago. Then in the second wave it was all about provider institutions trying to support under-served populations, and it was focused on the clinical use case and the business case.

The third wave is where we are now, and these are the drivers for the third wave of telehealth/telemedicine. In addition to under-served populations, we're recognizing there are quality and patient access business drivers within organizations. This is what is driving the adoption today.

The other is consumerism. We have organizations that are trying to avoid market leakage, improve patient access, trying to improve quality and continuum of care, and trying to help remote monitoring. Those are all institutional issues and payer issues that are trying to change how we deliver healthcare. I think understanding what is going to be out there is better for understanding why we're out there. And I think that helps us understand how we're going to move forward. 
Joel Reich [02:05]

Page 2 of 15

Dave, do you want to expand further on how you think about it?

\section{David Gruber [02:11]}

I use history as a predictor of change. And then I say what are the key learnings; and from there extract. There are a number of key learnings. When I go back probably, and I don't have the expertise you guys have in this area, but one thing is that I've been a technologist. To me a lot of this, at least in the early days, was technology in search of a market. In healthcare, what's really key to recognize is that there are so many advanced technologies. I spend my time today in analytics. And we look at where healthcare is relative to say Amazon and some other industries. We're way behind.

And so, the first question is why hasn't adoption occurred? And there are reasons why. And it's the system. We've got to look at that. Second, we have to look at the evolution of the technology over time. We started with telephonic, to video, and then we go from the computer to mobile. Okay, so we're increasing convenience for access.

We also have to look at the data; and right now, we have mostly structured data, but $80 \%$ of healthcare is unstructured data. There's huge value in terms of user-generated content that we're not taking advantage of at the moment. So that's another key trend.

We also have the advance of sensors. And so, the question is, when you integrate all these different data, what does that mean; and how do we generate insights? So that's a big takeaway. The big data revolution is a misnomer. It's not big data. To me, it's just activity in search of a market. The real issue is what does it mean for a specific patient who potentially has a series of co-morbidities. So, we're not treating conditions; we treat patients, and you have got think of co-morbidities.

The third key thing are the applications. Who are the right patients and the right conditions? And here are a couple numbers for you from Population Health in the commercial world, $5 \%$ of Medicare fee-for-service beneficiaries account for $43 \%$ of total 
1831. Reich. Moving

https://doi.org/10.30953/tmt.v2.44

Page 3 of 15

spending, the top $10 \%$ of the population account for $64 \%$ of overall health, with $25 \%$ accounting for $85 \%$ of all spending. ${ }^{1}$ What we care about is $10 \%$ to $25 \%$ percent of population. Forget everybody else. That's where the focus is. That's where the opportunity is. Chronic disease is where it's at going forward, with exceptions in that regard.

Access and convenience matter, and that was the great start. Someone had the great Eureka. Great! We provide access. But if there's no business model around it, it's going nowhere. And then the question is, "What are the payment models?" So, reimbursement is key.

And then obviously the workflow integration is key. I can't understate that. Where does it fit into the system? What we need to do is re-engineer the entire process of care in healthcare. But what I said before is all healthcare is local. Some of better than others. There are some very good functional systems out there-maybe $5 \%$, or $10 \%$, or whatever the number is.

The last part of that is, there's an element of behavioral change. What I've seen is that for nurses out there, telemedicine can be a threat. Maybe it's fewer visits. Fewer visits means fewer employees down the road. If you get the same level reimbursement why should they accept the technology in that regard.

Or, I could see an implementation per se. And I could tell you there's real weakness in the analytics in the United States. So, you get all these big data, but what does that mean, and who cares; and then does it integrate into the primary care record.

\section{Key Learnings from the Third Wave}

Richard Bakalar [05:20]

One of the things I think is very true is that when we think about healthcare, it's the doctor patient relationship and all the extended care givers in the network. And consumers now for the first time, consumers have a bigger financial responsibility and 
accountability, as well as healthcare accountability. They're actually taking healthcare personally and actually starting to engage in some of these things.

For example, we heard about Teladoc ${ }^{\circledR}$ earlier today. KPMG, LLP uses Teladoc as part of its health plan, but the adoption has been low. It's only $1.8 \%$; and of those, $90 \%$ were phone consults. So even though we have wonderful technology online capabilities, adoption is relatively low. And that's because of the fact that this is such a fractured or fragmented system. It isn't connected, and so one of the things that I think we're going to start seeing is integration of the business into the healthcare continuum. And so, telehealth 1.0. which is these episodic, kind of isolated events for e-visits is going to now morph into more of a continuum of care, more patient-centered care. So, as we talk about patient choice, just like patient choice has directed our retail industries and financial industries, I think our healthcare industry is going to become much more connected, and much more personal, and much more service-oriented than it has been in the past. And so, I think that's the main driver. Consumerism is going to drive transformation, and it's not going to be necessarily the traditional payers or even providers.

\section{David Gruber [06:48]}

I'm actually optimistic. Again, as a former Wall Street analyst, the toughest thing is the timing. You get the fundamentals right, but you've got to get the timing. And the other thing I want to emphasize is that there were 383 MSAs (Metropolitan Statistical Areas) in the United states, and everyone is different competitively and the like. So, I just keep coming back to that because l've seen it. You see one hospital and you see one hospital. You see one system. you see one system. So, I'm optimistic.

The big thing is on the employer side is high-deductible plans. I've done benefit work for some of the big companies, and so the brilliance of our managing costs has been shift more cost of the employees, and the amount that the company pays is less. That's not cost containment, that's cost shifting. And they're waking up to say we've pushed as much as we can on to the employees, we can't continue to do that. That was just make 

believe for the time being; but it did reduce their own costs. The byproduct of that is it does increase a little bit of engagement. The greater awareness that there's a huge variation across health systems in the United States.

There's huge provider variation. There's huge site of service variation. I'm not sure everybody realizes this, but if you do a CT scan (Computerized Axial Tomography) in a hospital versus the private doc you could be paying double. If you've got an infusion in the hospital (cancer infusion or you have rheumatoid arthritis) and you get infusion at home, it's $\$ 700$. If you get it in a hospital it's $\$ 3500$. No difference in outcome, no difference in the drug, $\$ 2800$ purely for the site of service. So, the transparency tools have not taken off. We can come back to that as to why.

But engagement is key. And I think we're going to get more of that because there's more out of pocket, but that ties into the whole literacy issue. Consumers are ignorant of healthcare. I'm ignorant of healthcare. I can't deal with insurance companies and the bills and trying to figure it out. And so, I call that purposeful obfuscation. There is no transparency. It's like getting your phone bill. You can't figure out the network cost versus the other costs. But I think what's key here is the whole literacy question. And we could think about numerical literacy, different kinds of literacy; but we've got to work through that.

And then the last thing is I spent three years at $J \& J$ in the Consumer Division, and my perspective turned 180 degrees because MDs are push people. We push solutions we don't listen, and what we need to do is become pull people. We need to create the environment to bring them in and say okay, how do we add value, and how do patients and their caregivers have more accountability? And I think with the Internet, and peerto-peer discussions, and all that other stuff there will be a bit of a societal change. So, it's kind of a years and process, and I'm really hopeful. But the way I think about this is I'm hopeful for the better healthcare systems who "get it." 
1831. Reich. Moving

https://doi.org/10.30953/tmt.v2.44

Page 6 of 15

And payment reform is really key. That's the fourth point, moving towards a value-based payment system is absolutely essential.

\section{The Growing Retail Healthcare Model (Wal-Mart)}

Richard Bakalar [09:47]

Just as a brief follow-up to that, I just came from a recent conference, and Walmart is becoming a major provider in primary care. And, in fact, a recent survey has demonstrated that patients (consumers) would be willing to pay up to $\$ 1,000$ dollars for an MRI (magnetic resonance imaging) scan at a Walmart, for example. And that seemed pretty shocking to me at first. But you think about it, the reason pharmacies in general are becoming a major provider in this space is because of price transparency. When you go to a Walmart you know how much it's going to cost for whatever services or products you get. When you go to a doctor's office or a hospital, that isn't the case. So, the retail space is going to drive providers to become much more accountable financially to the public. And I think that's going to help drive cost containment, significantly.

\section{David Gruber [10:28]}

But the part of that's really key is the limitations of the retail model. Nurse practitioners are not physicians. And so, when you look at their qualifications for an NP, it's pretty scary. In some states they're well trained, clinically. In other states, it's six months of school and some six months of clinical training. That's not somebody I want to take care of some complex co-morbid condition. So, what we have to do is look at what role are they playing?

The other part of Walmart model is that the retail is kind of the lower end stuff. They get the colds. They'll get a little bit into chronic disease, but they're not managing these complex co-morbidities. They're doing the one-offs, and looking where the margin potentially is. 
1831. Reich. Moving

https://doi.org/10.30953/tmt.v2.44

Page 7 of 15

The other part of the Walmart strategy is they have real radiologists on the other side to read the image. But if you do the image without the primary care, so what?

\section{Richard Bakalar [11:22]}

But that is what telehealth comes in. That's primary care plus. You've got the nurse practitioner in the clinic, but then you've got the specialist on-line. And so, you have that combination of both, which eventually will become a model, which will be very competitive to a primary care model.

\section{David Gruber [11:38]}

So, what we need, then, are data, because l've looked at big companies. But the reality is they talk about engagement. So, you look at health and wellness. You look at all these coaching programs and all the other stuff. So, I look at specialty pharma, and when you ask how do you measure outcomes? Does your case manager with the specialty pharma make a difference?

So we measure engagement. And I said, "How do you measure engagement?" "We make phone calls." They say we're engaged if we do three phone calls. And I say, "So what? Do you measure outcomes? What's the total cost of care, and what are the resource utilization measures?" And the answer I get back is there are no measures. "It's engagement."

So, I think what's really key here is that whatever you do in your business model there are these general terms. But in this data-enabled world they're going to be smart guys out there looking at this stuff, and say where does it really matter? And that's the opportunity. If you could really create value, I think it's a huge opportunity. Do you agree with that?

\section{Richard Bakalar [12:42]}

$100 \%$. 
Joel Reich [12:44]

Let's laser right, and make it real now. Let's go back to the senior population, and let's go to a use case. How about Massachusetts General Hospital?

\section{Richard Bakalar [12:54]}

What's interesting at Mass General, fast forward, I was doing this like say 20 some years ago, with very limited technology. Today we have very robust technology, and Mass General has a very robust telestroke program, but what they found is that there was another population, a subpopulation in the state of Massachusetts, that needed help as well. And that was a burn patients. There was a significant number of burn patients throughout the state that needed help. So rather than creating a separate siloed project around teleburn, what they did is to leverage all the infrastructure, all the technology that was already in place with telestroke and used it for teleburn.

They did it in three phases. The first phase was initially to look at triaging patients. Could they be treated locally, or do they need to be centralized at a central hub?

Second phase was then to be able to manage patients, ongoing. When they decided that they could help them remotely and use the same technology for the telestroke.

But the thing that was most dramatic for me is when they did a third phase where they took their existing rehab hospital, which was about three miles away from Mass General and leverage the fact that their acute care hospital was $100 \%$ full most of the time. Burn patients typically need a lot of surgeries, multiple surgeries, and it's very expensive to bring them to the acute care facility especially when you don't have beds available. So, what they did is they used their outpatient same day surgery for those burn patients from the rehab hospitals. They sent them back to rehab after the surgery and saved their acute care beds. They used the same surgeons that would manage them in acute care hospital for teleburns. 
So, what this accomplishes is two things One, is that allowed them to use a less expensive resources for the same thing and get very good results because they used the same doctors and the same patients, essentially. But what was even more impressive was the fact that they have less patients coming back to acute care for complications because they had ongoing continuous care from the same doctors whether they were seen in the acute care hospital or they were seen in rehab. Plus, they leveraged their resources in a rehab facility.

So, I think this is an example of how we can leverage existing technologies across specialties and make it more programmatic as opposed to single projects and departmental. And I think this was a great learning experience for me to see how you could do this very efficiently and very inexpensively and get really good ROI. Because they actually demonstrated fewer lost hospital beds and they also demonstrated fewer unplanned readmissions to the hospital. Both of those are very important proxies for quality in addition to cost.

\section{David Gruber [15:30]}

I think that's a great example, and what l'd be interested in hearing more about is how did they do it? What were the challenges?

Joel Reich [15:39]

What were those critical success factors; and I'm sure they didn't work swimmingly just out of the gate.

\section{Distinguishing Between a Project and a Program}

\section{Richard Bakalar [15:45]}

I was very focused and targeted. As mentioned earlier, targeted use cases are very important, but in general I think I want to speak to what distinguishes a project from a program? This is an image that's been in our program for the conference, as well. I don't like to use the word "telemedicine" because that tends to be a temporal description of what we're doing. The idea is using digital health or innovation to be able to help 
1831. Reich. Moving

https://doi.org/10.30953/tmt.v2.44

Page 10 of 15

improve delivery models. And what unfortunately most people focus on is the technology. And that's where we get into trouble because technology is necessary but not sufficient.

Probably, most important are the governance, and that's the key issue. When you have a closed system. I spent 25 years in the military. We had a closed system. Governance was even split there because we had the operational ships and we had the hospitals. I had to bridge those two different groups because they had different funding streams and different mission requirements. But in the military, it was all about the mission. It wasn't about the dollars. In the private sector, it's all about the business case; and so in order to get the business alignment you have to get all of the players to the table and have common purpose and common goals.

And I think probably the biggest challenge in going from a project to a program, is to bring those stakeholders together and think more broadly than just a single use case, but across the program.

The second is what are the things that you're going to be doing that are going to be useful. And what we don't realize is oftentimes we start with one thing but then we move into other things. So, in this case they started out with telestroke, but then they realized they could use the same thing for teleburns, with minimal additional cost.

And then finally to standardize your platform. That is one of the things we talked about-the concept of a horizontal platform as opposed to a vertical solution. We have too many appliances in telemedicine and not enough platforms. When you say an appliance, what is the difference? Well, often you have a dedicated box that only does one thing, and it's very expensive and when you're talking about avoiding hospitalizations it pays for itself pretty quickly. But that's a small percentage of the total population. That represents $1 \%$ to $2 \%$ of the entire population. If you want to make it more broadly available you have to use common platforms. A good example of that is your phone, as you mentioned earlier. Your smartphone is not only a voice 
1831. Reich. Moving

https://doi.org/10.30953/tmt.v2.44

Page 11 of 15

communicator now but it's data communicator as well. So, having horizontal platforms in telehealth is going to allow us to scale and become sustainable. So those three top boxes I think are the most important (Figure 1).

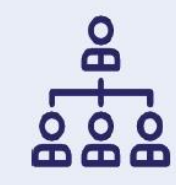

Governance and Organizational Alignment

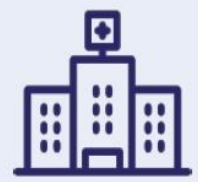

Clinician and Staff Engagement

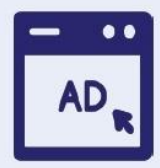

External Program Marketing

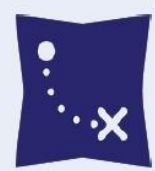

Clinical Services Target Operating Model (TOM)

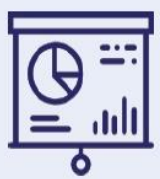

Performance Management Framework

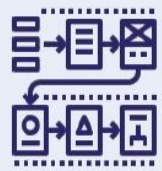

Vendor Management

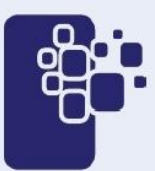

Technology Platform and Management

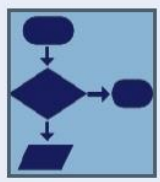

Practice Guidelines and Process/Data Integration

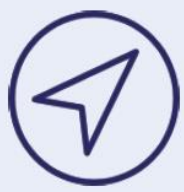

Patient Navigation and Experience

KPMG

Figure 1. Building best in class programs

And of course, engagement and performance management, as was mentioned, is important. The communication and marketing is very important, and it used to be done early in the process because we're dealing with humans we're not dealing with machines. We have to have people who understand and are able to navigate through these new and new disruptive models,

So, I think understanding these critical success factors can help organizations migrate from where they are to where they often want to go. 
1831. Reich. Moving

https://doi.org/10.30953/tmt.v2.44

Page 12 of 15

It's not overtly there, and it's also follow the money. I mean we've got to get the payment incentives for right for all the participants in this. Or else you will that push away that you described earlier potentially from someone sees it as a take away of the visit. So that critical to get around the incentives.

\section{Q\&A}

For the burn program you described, is this targeted to home health? [18:48]

\section{Richard Bakalar [18:54]}

This is not for home telehealth. This is for a rehab facility that is skilled and has specific expertise in burn patients for rehab. It's the interim care between home and acute care; and they have the experience and they have the capability. What they don't have are the surgeons; and those are ones that are being inserted remotely. It's the expertise they're projecting, not the not the hands-on care.

\section{David Gruber [19:19]}

What we've talked about here is mostly, you know, we talk about the use cases, right. These are the specialties: teleICU, telederrn, teleburn, teladerm, teleradiology.

What you are addressing is where we have to go, which is that when you take these patients you say they go home. When we look at chronic disease management what we need to do is, let's say you take on orthopedic replacement. The risk is fall. Going to the bathroom in the beginning, falling, and its complications. As part of our healthcare services do we do fall prevention in the house? Do we look at the floors? Do we look at the slipperiness? Do we look at the bathroom and are the bars in there? Do we have a caregiver $24 / 7$ ?

And so, where I see opportunity is in the future when we go to payment reform, when we look at the total cost of care. Now, it pays to keep them out of the LTAC (long-term acute care) in terms of the rehab. Keep them out of the nursing home. Send them home, do the home care: put in the bars in the bathroom and save a lot of money at the 
1831. Reich. Moving

https://doi.org/10.30953/tmt.v2.44

Page 13 of 15

end of the day. That's kind of the perfect world. We're not there yet. That's where we want to go, but there are people who are thinking about stuff like that and doing stuff like that.

\section{Do you have recommendations for telehealth and contingency care or for unexpected medical needs? [20:26]}

Richard Bakalar [20:32]

Just to your point, this is a patient center view of the world. Unfortunately, most of the world today is a provider-centered. It's a care setting based on where the provider is, and that's where the services are often offered. And there is very poor continuity across those. So, to your point on contingency operations or situations where we have trauma or unexpected care, the thing you want, the first tenant is don't delay care. That's number one. You have to have the primary care at the point of care. You have to have the emergency facilities capable at the point of care, with the expertise of doing initial care.

The other thing is, what you can do with telehealth is get expertise projected. When the Navy Surgeon General started the program, he said move information not people. So, we projected specialty care to the point of care, but we still had to have the primary care in the setting of where the patient was. A good example of that is when we did Navy ships we had a great success. The cruise ships have very poor success. And so, they don't have the expertise to be able to receive the care.

Plus, the motive, the typical protocol on a cruise ship, is to move the patients off the ship onto land, and then have them transported elsewhere. On a military ship, there 250 or 300 miles off shore, and they can't be moved. They have to manage them on board.

The key with emergency or contingency care is you have to have good primary care at the point where the patient is and you can project specialty expertise to them through telemedicine. 
1831. Reich. Moving

https://doi.org/10.30953/tmt.v2.44

David Gruber [21:48]

Page 14 of 15

I was in Israel actually looking at some trauma stuff. It's very cool. They talk about

disasters. Israel is the best in the world, unfortunately. And so, what they do is they

have this truck. It's special, and it shoots a camera up 40 feet in the air-a $360^{\circ}$ camera that's hooked into all the trauma centers in the local area. And then they have triaging. So, they could see remotely what's happening in the field of view. And then they get the surgical teams and whoever ready to go. Situation awareness.

And because it's interoperable for mass casualties, because they deal with it so they are prepared for it. So, this way they have the guys on the field who do the triage and then they know they have only " $x$ " number of level-one centers and level-two. So, the right patients go to the right centers, and that's part of it.

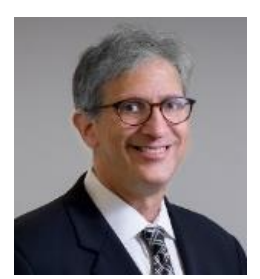

David Gruber is Managing Director and Director of Healthcare Research at Alvarez \& Marsal.

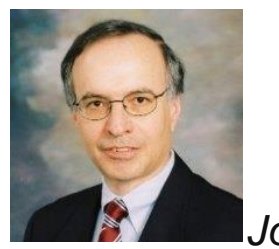

Joel J. Reich, MD, FACEP, Senior Vice President for Medical Affairs and Chief Medical Officer of Eastern Connecticut Health Network.

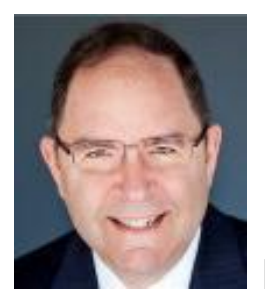

Richard S. Bakalar, MD, Former ATA President and current Managing Director, Advisory Services—Health Solutions (Virtual Care), KPMG. 
1831. Reich. Moving

https://doi.org/10.30953/tmt.v2.44

Page 15 of 15

1. Research in Action. June 2006: \#19. The High Concentration of U.S. Health Care Expenditures. URL:

https://archive.ahrq.gov/research/findings/factsheets/costs/expriach/expendria.pdf. Accessed 11/16/17.

This is an open access article distributed in accordance with the Creative Commons Attribution Non-Commercial (CC BY-NC 4.0) license, which permits others to distribute, adapt, enhance this work non-commercially, and license their derivative works on different terms, provided the original work is properly cited as first published in TeleHealth and Medicine Today, and the use is non-commercial. See:

http://creativecommons.org/licenses/by-nc/4.0. 